\title{
Outrage at planned changes to Quebec IVF
}

A $t$ the age of 44, Nadia Mahfoufi finally got pregnant after numerous rounds of invitro fertilization (IVF). But if Bill 20, tabled by Quebec Health Minister Gaétan Barrette on Nov. 28, had been enacted, Mahfoufi argues she would not be holding her six-monthold baby boy in her arms today.

The provincial government is proposing a drastic cut to funding for IVF treatments, which have been heavily subsidized since 2010. If the bill is approved, the government will cover only one round of IVF treatment and artificial insemination, and only for women between the ages of 18 and 42. The province claims the changes will save nearly $\$ 50$ million a year.

In effect, these proposed cuts mean Quebec could go from being the most generous jurisdiction in terms of assisted

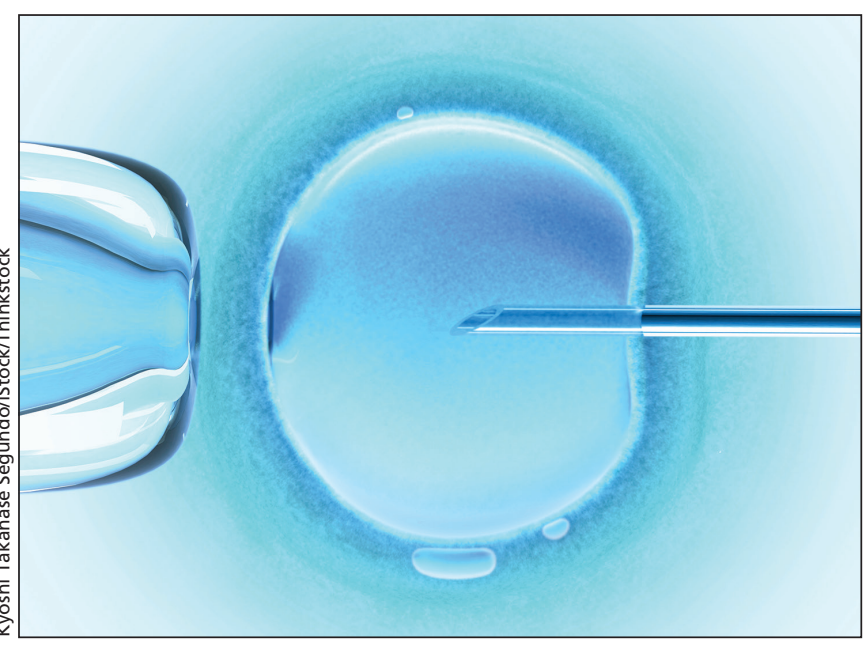

Quebec now funds up to three rounds of IVF, but proposed legislation would reduce that to one. reproduction to being one of the most restrictive. Quebec is now the only province that funds up to three rounds of IVF. Last year, Ontario agreed to fund one round of IVF per woman, but in most provinces, IVF is paid for privately.

The bill is supported by a report from Robert Salois, the province's Health and Welfare Commissioner, which states that IVF costs exploded from about $\$ 16$ million a year in 2010 to over $\$ 80$ million by 2012 .

Not surprisingly, Bill 20 has prompted an outcry from some patient groups and physicians.

"Quebec went from being the leader in North America in terms of having the most comprehensive coverage to being really at the back of the line," says Neal Mahutte, president of the Canadian Fertility and Andrology Society. The society is working on a policy document about age limits for fertility treatments.

Bill 20's stipulation that IVF be carried out only on women between the ages of 18 and 42, is unethical, says Dr. Seang Lin Tan, a reproductive endocrinologist in Montréal. "I understand it is a cost saving rational, but the government has no business in deciding the age of a women's motherhood."
"It is clear that the law in question would have prevented us from realizing our dream," Mahfoufi says. "Frankly, we would have certainly left Quebec."

The bill also prohibits those working in the "health and social services sector" from directing women over the age of 42 to another jurisdiction for treatment, or face fines of up to $\$ 50000$. Tan, who estimates he could lose more than $30 \%$ of his patients if the bill passes, says this edict is "crazy."

Joanne Beauvais, press attachée to the minister explains that "IVF procedures are considered too risky after the age of 42 and therefore it would be irresponsible for a doctor to recommend it elsewhere as well."

"This is draconian legislation," says Mahutte. "Can you imagine what will happen to patients over the age of 42 who already have frozen eggs or embryos in Quebec? It will be illegal

for Quebec physicians to use those eggs or embryos and illegal for us to direct the patient for care elsewhere." If the patient manages to get a physician outside Quebec, "how is she supposed to arrange the transfer of her genetic material?" asks Mahutte. "This requires our assistance, but is apparently illegal and punishable with a $\$ 50000$ fine. How does that make any sense?"

Bill 20 is extremely disappointing adds Virginie Kieffer president of the Association des couples infertiles du Quebec, which represents hundreds of couples. "It is an enormous deception for us. We fought so hard to get support for these couples. Infertility is a medical condition. We feel that if the government had better framed the program, the cost would not have skyrocketed this way." She says the age cap is discriminatory.

However, Françoise Bay-

lis, professor and Canada Research Chair in Bioethics and Philosophy at Dalhousie University in Halifax, disagrees: "There is significant evidence in the literature that advanced maternal age is harmful to both the infant and the mother, in this sense I do not think that the bill infringes on women's rights."

Baylis does agree that women have the right to make their own reproductive choices. "In any case, there is nothing in the law that prevents a woman over 42 seeking IVF treatment outside of Quebec. The law only prohibits those who are working 'in the health and social services sector' from referring women over 42 to another jurisdiction."

The new bill is scheduled for debate at the National Assembly of Quebec in the spring of 2015. - Véronique Morin, Montréal, Que.

CMAJ 2015. DOI:10.1503/cmaj.109-4966 